\title{
EDITORIAL
}

\section{Editorial: This Year | March 2016, The Latest News about the Sleep and Hypnosis}

\author{
Mehmet Yucel Agargun ${ }^{1 *}$ \\ ${ }^{1}$ Istanbul Medipol University, School of Medicine, Department of Psychiatry, Istanbul, Turkey
}

I am honored to inform you that Sleep and Hypnosis is now published with its new version. Since 1999, the journal has been published regularly and had outstanding contributions in the fields of sleep, dreaming, and hypnosis. By the end of 2015, the journal was renovated by my three deputy editors, Drs. Selvi, Güleç, and Boysan. My specific thanks to them. Hopefully, Sleep and Hypnosis would be grown and developed under the strong editorship of my colleagues. I hope Sleep and Hypnosis would be widely acknowledged for its high academic standards and for being a leading journal with high impact factor.

With this issue, Sleep and Hypnosis expands its advisory board. We have invited several new members of the advisory board and are delighted to report they have accepted our invitation. I appreciated old and new members of the advisory board for developing a useful vehicle, Sleep and Hypnosis, for the clinicians and researchers worldwide.

Fifteen years ago, I asked a question `is there a need for another sleep or hypnosis journal?' even there were about a dozen of sleep and hypnosis journals. Sleep and Hypnosis differed from other related journals because this journal is interested not only in the application of

*Correspondence: myagargunakure.com.tr

Dr. Mehmet Yucel Agargun, Istanbul Medipol University, School of Medicine, Department of Psychiatry, Bağcılar, Istanbul, Turkey neurobiological sciences to the study of sleep and hypnosis but also in behavioral/cognitive, psychosocial, and socio-cultural aspects of these phenomena. We plan to publish research results from the broad spectrum of sleep, chronobiology, dreaming, and hypnosis, including important findings pertinent to the etiological, epidemiological, pathophysiological, pathogenetical, diagnostic, clinical, experimental, laboratory, and therapeutically aspects. On the other hand, there is a strong and plausible association between sleep states and hypnotic phenomena. The journal focuses on this association and on clarifying the underlying mechanisms of these phenomena.

Throughout past fifteen years, multidisciplinary approaches have been particularly welcomed. The basic, applied, and clinical studies have been published. We look forward to new contributions, which will significantly enhance the body of knowledge about sleep, circadian rhythms, dreams, and hypnosis. The journal is already abstracted or indexed by several. We expect this list will grow in near future.

What we believe is that, Sleep and Hypnosis will continue to play its important part in promoting scientific enterprise in the realms of sleep, chronobiology, dream and hypnosis. Looking forward to meeting you in future issues through many years, which -hopefully - would bring peace and prosperity for all humankind.
Sleep and Hypnosis

\section{Submit your manuscript at} www.sleepandhypnosis.org

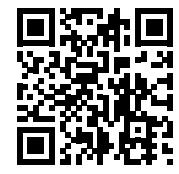

Mehmet Yucel Agargun, MD

Professor of Psychiatry

Editor-in-Chief 